\title{
Applied Hydrogen Storage Research and Development: A Perspective from the U.S.
} Department of Energy

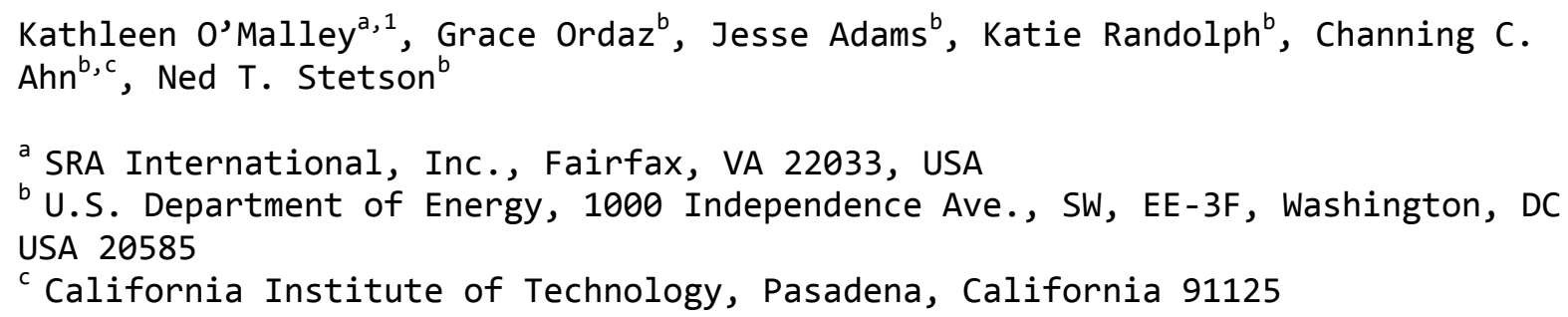

\section{Abstract}

To enable the wide-spread commercialization of hydrogen fuel cell technologies, the U.S. Department of Energy, through the Office of Energy Efficiency and Renewable Energy's Fuel Cell Technology Office, maintains a comprehensive portfolio of R\&D activities to develop advanced hydrogen storage technologies. The primary focus of the Hydrogen Storage Program is development of technologies to meet the challenging onboard storage requirements for hydrogen fuel cell electric vehicles (FCEVs) to meet vehicle performance that consumers have come to expect. Performance targets have also been established for materials handling equipment (e.g., forklifts) and low-power, portable fuel cell applications. With the imminent release of commercial FCEVs by automobile manufacturers in regional markets, a dual strategy is being pursued to a) lower the cost and improve performance of high-pressure compressed hydrogen storage systems while b) continuing efforts on advanced storage technologies that have potential to surpass the performance of ambient compressed hydrogen storage.

\section{Keywords}

Carbon fiber; Metal hydrides; Chemical hydrogen storage; Sorbents; Compressed hydrogen

\section{Introduction}

The U.S. Department of Energy's (DOE) Office of Energy Efficiency and Renewable Energy (EERE) Fuel Cell Technologies Office (FCTO) is dedicated to enabling the widespread commercialization of hydrogen and fuel cell technologies through basic and applied research, technology development and demonstration (RD\&D), and through diverse efforts to overcome institutional and market challenges [1].

1 Present address: Stanford University, Palo Alto, CA 94305, USA 
FCTO supports near-, mid-, and long-term RD\&D efforts for hydrogen and fuel cell use across a variety of sectors addressing applications that include portable power systems, materials handling or specialty vehicle applications and ultimately, light-duty vehicles. Early market applications like stationary power and specialty vehicles are beneficial in enabling the development and commercialization of fuel cell electric vehicles (FCEVs) through public education about hydrogen and fuel cells, vendor supply chain development and real world experience in the performance of this technology. The Hydrogen Storage Program (Program) within FCTO focuses on developing hydrogen storage technologies to enable cost-effective operation of fuel cell devices, including automobiles with a range of at least $500 \mathrm{~km}$. This paper discusses the forthcoming deployment of FCEVs globally and how the DOE is addressing the need for focused development of materials capable of meeting material requirements for hydrogen storage to enable FCEVs performance on par with conventional vehicles.

Fuel cells were originally invented in the early 1800 s with intense development in the late 1960s and early 1970s for the NASA Apollo program [2]. GM developed the first fuel cell passenger car in 1966 and various automakers (Daimler, Honda, Ford, BMW, and Hyundai) developed their own versions through the following decades [2]. Today, FCEVs are once again at the forefront of alternative transportation approaches, with several major automakers committed to commercialization plans in the 2015-2017 timeframe. Hyundai has already leased their first Tucson Fuel Cell SUVs in Southern California [3] and Toyota and Honda will be offering hydrogen fuel cell models in 2015 [4]. The issue of infrastructure is being actively addressed with many countries providing funding, analysis, and station investment. Public-private partnerships have been established in the U.S. ( $\mathrm{H}_{2} \mathrm{USA}$ ), Japan (HySUT), Germany ( $\mathrm{H}_{2}$ Mobility), United Kingdom (UKH $\mathrm{H}_{2}$ Mobility), and Denmark, Norway and Sweden (a combined effort under the Scandinavian $\mathrm{H}_{2}$ Highway Partnership) [5]. In the U.S., eight states signed a Memorandum of Understanding to put 3.3 million zero-emission vehicles on the roads by 2025 . California has devoted over $\$ 45$ million to 28 new hydrogen stations and plans to invest $\$ 20$ million annually through 2023 to reach a goal of 100 stations throughout the state [6]. FCEVs are truly on their way.

The successful commercialization of FCEVs requires that FCEVs meet customer's expectations and provide performance similar to conventional gasoline vehicles. FCTO has developed, through U.S. DRIVE, a government-industry partnership between the DOE, automakers, energy companies, and utilities, an extensive set of performance targets that would make FCEVs competitive across the majority of traditional vehicle classes. The onboard hydrogen storage targets for automotive applications were most recently updated in 2012 and a complete list of the targets and current status against gravimetric capacity, volumetric capacity, and storage system cost can be found in FCTO's Multi-Year Research, Development, and Demonstration Plan [7].

\section{Discussion}

2.1 Compressed $\mathrm{H}_{2}$ storage is currently the most mature option for present and near-term deployment and automakers have incorporated 700-bar compressed hydrogen storage systems into their initially deployed commercial vehicles. A summary of performance for a current representative 700-bar compressed $\mathrm{H}_{2}$ system is shown in Fig. 1 where the shaded areas indicate the extent to which individual performance metrics have been satisfied.

\section{[Insert figure 1]}


Based on standards developed in coordination with automotive, energy and gas companies, the initial hydrogen infrastructure will rely on fueling stations designed to refuel 700-bar compressed $\mathrm{H}_{2}$ storage systems. Onboard hydrogen storage technology for automobiles in the present FCEV rollout is based on Type IV carbon fiber composite overwrapped pressure vessels (COPVs). Current compressed $\mathrm{H}_{2}$ systems do not meet volumetric and cost targets for hydrogen storage but are close to meeting gravimetric capacity targets and have been demonstrated in concept vehicles and demonstration projects. Despite being a relatively mature technology with robust performance, 700-bar compressed $\mathrm{H}_{2}$ systems still require significant cost reductions to truly enable widespread commercialization of FCEVs and are not ideal for all vehicle platforms, particularly smaller vehicle models. Current costs for 700 -bar compressed $\mathrm{H}_{2}$ systems are $\$ 17 / \mathrm{kWh}$, more than double the ultimate storage target, with carbon fiber and balance-of-plant components accounting for over $90 \%$ of the cost [8].

The Program presently pursues a dual strategy to address the onboard vehicle storage challenge with efforts in a) 700-bar compressed $\mathrm{H}_{2}$ storage systems and b) advanced technologies including cold/cryo-compressed $\mathrm{H}_{2}$ and materials-based (metal hydrides, chemical hydrogen storage, and sorbents) hydrogen storage. Advanced materials-based storage has the potential to meet all the automotive targets but a timely, focused effort on development of materials with required properties is needed if FCEVs are to ultimately incorporate these technologies. The Program supports efforts in critical areas for compressed $\mathrm{H}_{2}$ and materialsbased systems to overcome barriers regarding cost, volume, weight, refill time, and cycle-life. Specific areas being addressed for compressed $\mathrm{H}_{2}$ storage include cost reduction, primarily through development of lower cost carbon fiber composites, and improved system design and manufacturing. Specific areas being addressed for advanced materials-based systems include novel materials discovery through computational and experimental efforts and complete system modeling, engineering design and performance validation.

2.2 The Program supports efforts to reduce the cost of carbon fibers, focusing on lower-cost precursors for high-strength carbon fiber. At Oak Ridge National Laboratory (ORNL) for instance, work is being supported to develop highmanufactured volume textile-grade polyacrylonitrile (PAN) precursor fibers that are competitive with the specialty PAN precursor fibers that are used presently for high performance applications. This effort is anticipated to result in a carbon fiber cost reduction by as much as $25 \%$ [9]. A promising precursor material has been identified and conversion process parameters (stabilization, oxidation, carbonization) optimized, with current carbon fiber exceeding the targets of 4500 $\mathrm{MPa}$ tensile strength and $240 \mathrm{GPa}$ modulus [10]. Other work at ORNL is focused on developing melt-processable PAN precursors, where lower cost manufacturing compared to conventional wet fiber spinning is expected due to lower capital and processing costs, thereby offering the potential to reduce carbon fiber costs by $>25 \%$ [11]. After demonstrating the feasibility of the melt-spinning process for high-PAN content fibers, alternative formulations are being developed to overcome challenges, particularly related to chemistry (workable materials, effective plasticizers) and processing (cost-effective spinning, optimized conversion process). Glass fiber composites can have substantially lower cost than carbon fiber, but are typically not used in 700-bar COPVs due to a substantial increase in mass. However the Program is supporting efforts at PPG Industries. They have demonstrated an ultra-high-strength glass fiber with a tensile strength of approximately $5500 \mathrm{MPa}$. This glass fiber is projected to have the potential to reduce the composite costs for 700 -bar COPVs by at least $50 \%$. 
In an effort by Materia, Inc., a low-viscosity, high toughness thermoset resin is being investigated in the place of traditional epoxy resins. Instead of the typical wet-winding process to manufacture COPVs, Materia will use vacuum assisted resin transfer molding (VARTM). The VARTM process is expected to result in less resin waste and fewer voids in the composite layers, when coupled with the higher toughness, a potential for $30 \%$ reduction in cost along with a $20 \%$ reduction in mass is projected.

The Program also supports efforts addressing the cost and weight of system balance of plant components. Due to its relative resistance to hydrogen embrittlement, 316/316L austenitic stainless steel is most commonly used. Sandia National Laboratories is using the ANSI/CSA CHMC 1 standard methodology to screen commercial steels to identify other potential candidates for use [12]. The ANSI/CSA CHMC 1 standard provides uniform test methods for screening materials for service in hydrogen applications [13]. This approach emphasizes identifying materials that are capable of withstanding fatigue stress cycling in a hydrogen environment instead of relying on changes in tensile strength when exposed to hydrogen. Through identification and certification of higher strength steels for use in balance of plant components, both mass and costs are expected to decrease.

2.3 While many promising cost reduction technologies for compressed $\mathrm{H}_{2}$ systems are in development, materials-based storage systems have the potential to meet all of the ultimate DOE targets for onboard vehicle storage. Efforts in materials-based hydrogen storage need to focus on relevant materials that, when incorporated into a complete system, have the potential to meet the system-level onboard hydrogen storage targets. This focus is imperative if materials-based storage is to impact transportation applications given the time required to incorporate new technologies into consumer vehicles, especially in light of the initial vehicle and infrastructure standards that are currently being implemented. The Program has identified requirements for metal hydride, chemical hydrogen, and adsorbent materials to satisfy system-level targets for onboard vehicle storage through the efforts of the Hydrogen Storage Engineering Center of Excellence (HSECOE). The analysis by the HSECoE shows that a metal hydride would need a capacity of at least 10-11 wt\% hydrogen with an enthalpy of $25-27 \mathrm{~kJ} / \mathrm{mole}$ $\mathrm{H}_{2}$ (to minimize the consumption of significant quantities of stored hydrogen during desorption) [14]. No metal hydride as yet is foreseen to meet this challenging target. Chemical hydrogen systems based on either alane or ammonia borane can already achieve many of the 2017 technical targets even when incorporated into a tank as a $50 \%$ mass-loaded slurry, although the overall fuel cost and well-to-power plant efficiency for these systems are at present intractable problems.

In support of the advancement of sorbent material systems through the HSECOE, the construction, testing, and evaluation of two sorbent prototypes (hex-cell and MATI) using MOF-5 as a surrogate adsorbent is proceeding [15]. One benefit of adsorbents is that throughout the well-to-power plant delivery, hydrogen remains in molecular form. One of the outstanding challenges for sorbent systems however, is their volumetric density. Given that the amount of fuel carried onboard a vehicle may be more sensitive to available onboard space available for the storage system rather than the system's mass [16], a better recognition of a material's volumetric hydrogen density is necessary for sorbent-based research. As the van der Waals dimension [17] of molecular hydrogen is large when compared to the dimensions of atomic interstitial hydrogen, the volume occupied by either adsorbed gas or even liquid hydrogen falls short of the densities that can be achieved in either metals [18], or complex or chemical hydrogen media, and short 
of the densities required for vehicle applications. Moreover, the generally weak interaction [19] between adsorbate gas and adsorbent surface requires low temperatures, such as $77 \mathrm{~K}$, for relevant hydrogen quantity uptake. As the available surface area of an adsorbent has generally been the criterion for maximizing uptake, research has typically been devoted to achieving ever higher specific surface area materials without regard to the consequence that this approach leads to extremely low density adsorbents with concomitantly lower volumetric density levels of hydrogen uptake. As gas law behavior begins to dominate in large meso-pore volume adsorbents, efforts that maximize surface area consistent with maximizing micro-pore volume offer possible solutions to the volumetric density problem. A trend [20] that only regards adsorbent porosity without regard to pore dimensions is noted in Fig. 2 where volumetric hydrogen density is plotted as a function of porosity and is shown to decrease with increasing porosity. Maximizing only micro-pore volume would minimize the lowering of volumetric hydrogen density. We note also that the recent trend of reporting "total" uptake from materials in single crystal form is of limited relevance as adsorbents are generally powders that need to be compacted [21] and such compaction leads to effective bulk densities that are lower than single crystal densities given the random packing of powders. Consequently, in addition to the effort on surrogate adsorbents, novel and innovative materials approaches are supported by the Program to further advance the status of onboard hydrogen storage for FCEVs.

\section{[Insert figure 2]}

\section{Acknowledgements}

The authors would like to thank all the researchers supported through the U.S. Department of Energy Fuel Cell Technologies Office's Hydrogen Storage Program, whose work contributed to the results described in this paper. Thanks go especially to David Warren and Felix Paulauskas of Oak Ridge National Laboratory and the partners in the Hydrogen Storage Engineering Center of Excellence for their contributions.

[1] The Department of Energy Hydrogen and Fuel Cells Program Plan; http://energy.gov/sites/prod/files/2014/03/f12/program plan2011.pdf.

[2] Fuel Cell Today, Fuel Cell Electric Vehicles: The Road Ahead;

http://www.fuelcelltoday.com/media/1711108/fuel cell electric vehicles - the road ahead v3.pdf.

[3] http://www.hyundainews.com/us/en-us/Media/RelatedReleases.aspx?mediaid=40852

[4] http://www.reuters.com/article/2014/03/25/us-honda-motor-fuelcells-idUSBREA2O1PR20140325

[5] H2USA - http://energy.gov/articles/energy-department-launches-public-private-partnership-deploy-hydrogen-

infrastructure, HySUT - http://www.theicct.org/sites/default/files/HySUT Report June5 2012 Rev1.pdf,

H2Mobility - http://www.now-gmbh.de/en/mobility/mobility-of-tomorrow/cars-buses-and-public-fuellingstations/h2-mobility-development-of-a-network-of-hydrogen-refueling-stations-in-germany.html, UKH2Mobility http://www.itm-power.com/project/ukh2mobility/, Scandinavian H2 Highway Partnership -

http://www.scandinavianhydrogen.org/

[6] http://www.energy.ca.gov/releases/2014 releases/2014-05-

01 hydrogen refueling stations funding awards $\mathrm{nr} . \mathrm{html}$.

[7] http://energy.gov/sites/prod/files/2014/03/f12/storage.pdf

[8] Onboard Type IV Compressed Hydrogen Storage Systems-Current Performance and Cost, http://hydrogen.energy.gov/pdfs/13010 onboard storage performance cost.pdf.

[9] http://www.hydrogen.energy.gov/pdfs/review14/st099 warren 2014 o.pdf

[10] Annual Progress Report 2014, in press, , D. Warren, ORNL at http://www.hydrogen.energy.gov 
[11] http://www.hydrogen.energy.gov/pdfs/review14/st093 paulauskas 2014 o.pdf

[12] http://www.hydrogen.energy.gov/pdfs/review13/pd025 somerday 2013 o.pdf

[13] http://webstore.ansi.org/RecordDetail.aspx?sku=ANSI\%2FCSA+CHMC+1-2014, accessed 27 October 2014

[14] http://www.hydrogen.energy.gov/pdfs/progress12/iv d 1 anton 2012.pdf

[15] http://www.hydrogen.energy.gov/pdfs/progress13/iv b 1 anton 2013.pdf

[16] http://www.hydrogen.energy.gov/pdfs/review13/st010 veenstra 2013 o.pdf

[17] J. Koresh, A. Soffer, Study of Molecular Sieve Carbons, J. Chem. Soc-Faraday Transactions, 76 Part 12 (1980) 2472-2485.

[18] D.G. Westlake, Hydrides of Intermetallic Compounds: A Review of Stabilities, Stoichiometries and Preferred Hydrogen Sites, J. Less-Common Metals, 91 (1983), 1-20.

[19] E.L. Pace and A.R. Siebert, Heat of adsorption of parahydrogen and orthodeuterium on Graphon, J. Phys. Chem. 63 (1959) 1398-1400.

[20] J. Goldsmith, A.G. Wong-Foy, M.J. Cafarella and D. J. Siegel, Theoretical Limits of Hydrogen Storage in Metal-Organic Frameworks: Opportunities and Trade-Offs, Chem. Mater 25, (2013), 3373-3382.

[21] J.J. Purewal, D. Liu, J. Yang, A. Sudik, D.J. Siegel, S. Maurer, U. Muller, Increased volumetric hydrogen uptake of MOF-5 by powder Densification, Intl. J. Hydrogen Energy 37 (2012) 2723-2727. 


\section{Gravimetric Density}

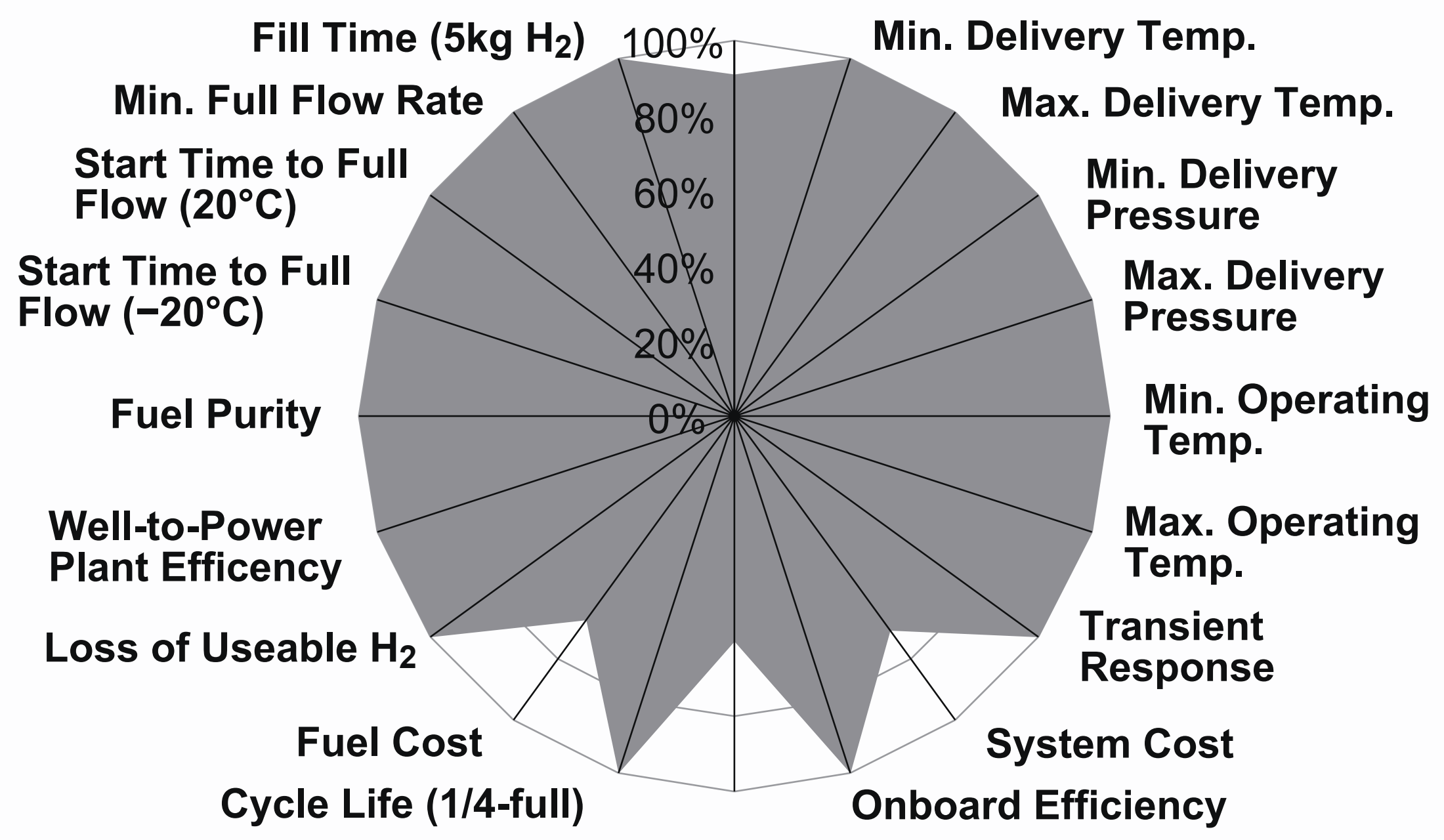

Volumetric Density 
Figure 2

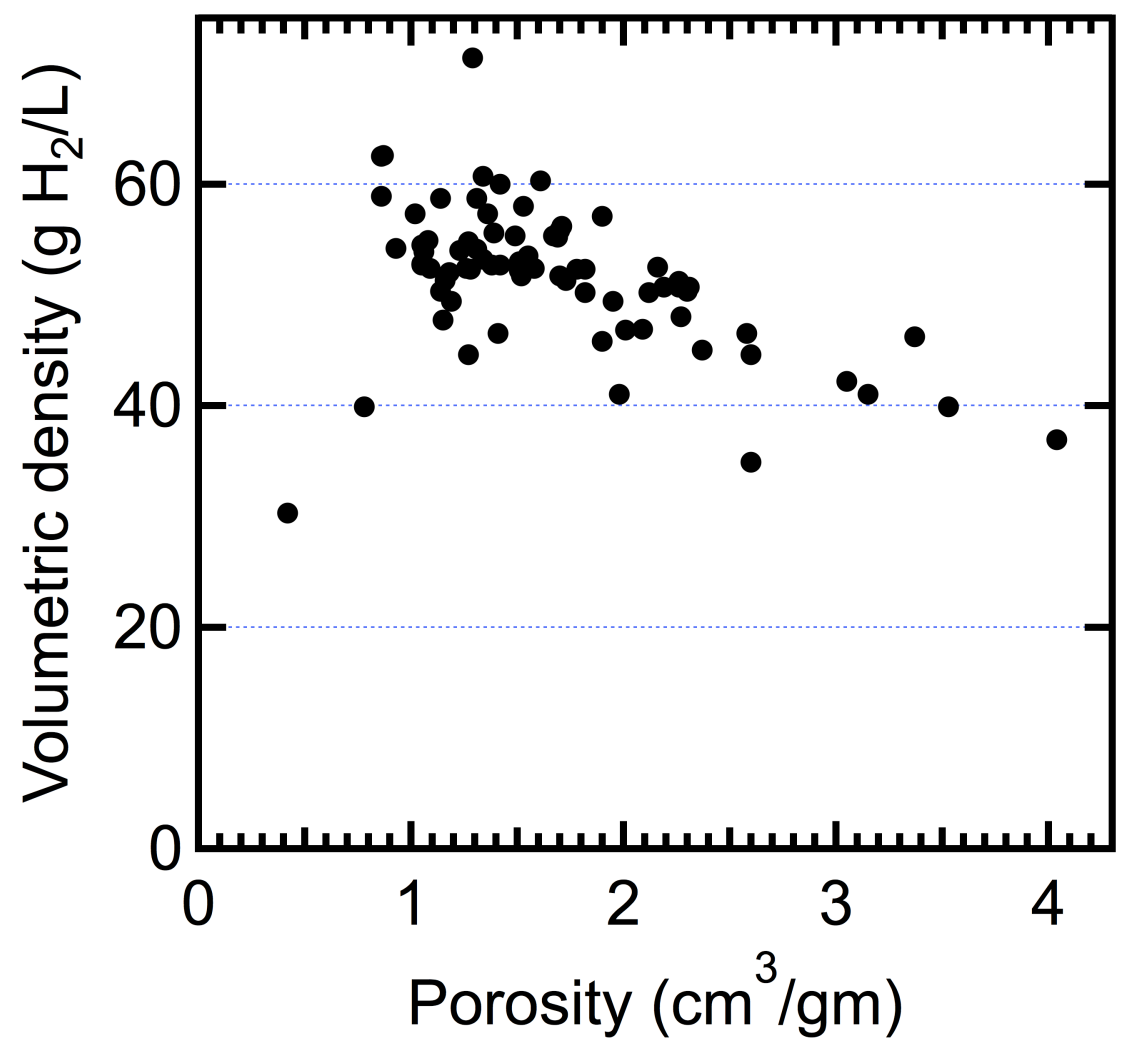


Figure 1. Chart showing performance of a current 700-bar Type IV single tank system [8]. Shaded areas indicate the extent to which performance metrics have been achieved relative to 2017 DOE targets.

Figure 2. Decrease in volumetric hydrogen density as a function of increasing porosity that accompanies increasing surface area. Trend is observed from calculated data [20] where no distinction is made between micro- and meso-pore volume contributions. 